\title{
Alumni Development for Aquinas High School
}

Mazen Mokhtar | Mark Kumler, PhD | MS GIS Program | University of Redlands

\section{Project overview:}

Aquinas High School is a private Roman Catholic High School in San Bernardino, California, that used the application of Geographic Information Systems to solve its current marketing and development issues. By compiling data from the Census Bureau of basic demographic and socioeconomic data, an interactive map was created that displays pertinent information on current students and alumni. Through use of this interactive map the school is able to access information that will aid in attracting new students and identifying areas for alumni development.
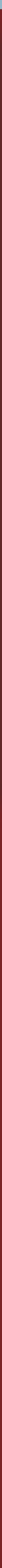

Zoom to Get Directions

\section{Goals \& Objectives:}

The main goal for the project is a web application (interactive map), that implements market analysis for the current student and alumni. The final product for the spatial analysis will feature layers of analysis results. The specific objectives are:

- A file geodatabase for Aquinas High School.

- The final analysis featured as layers displaying neighborhood results, through the use of ArcGIS Online.

- An interactive map.

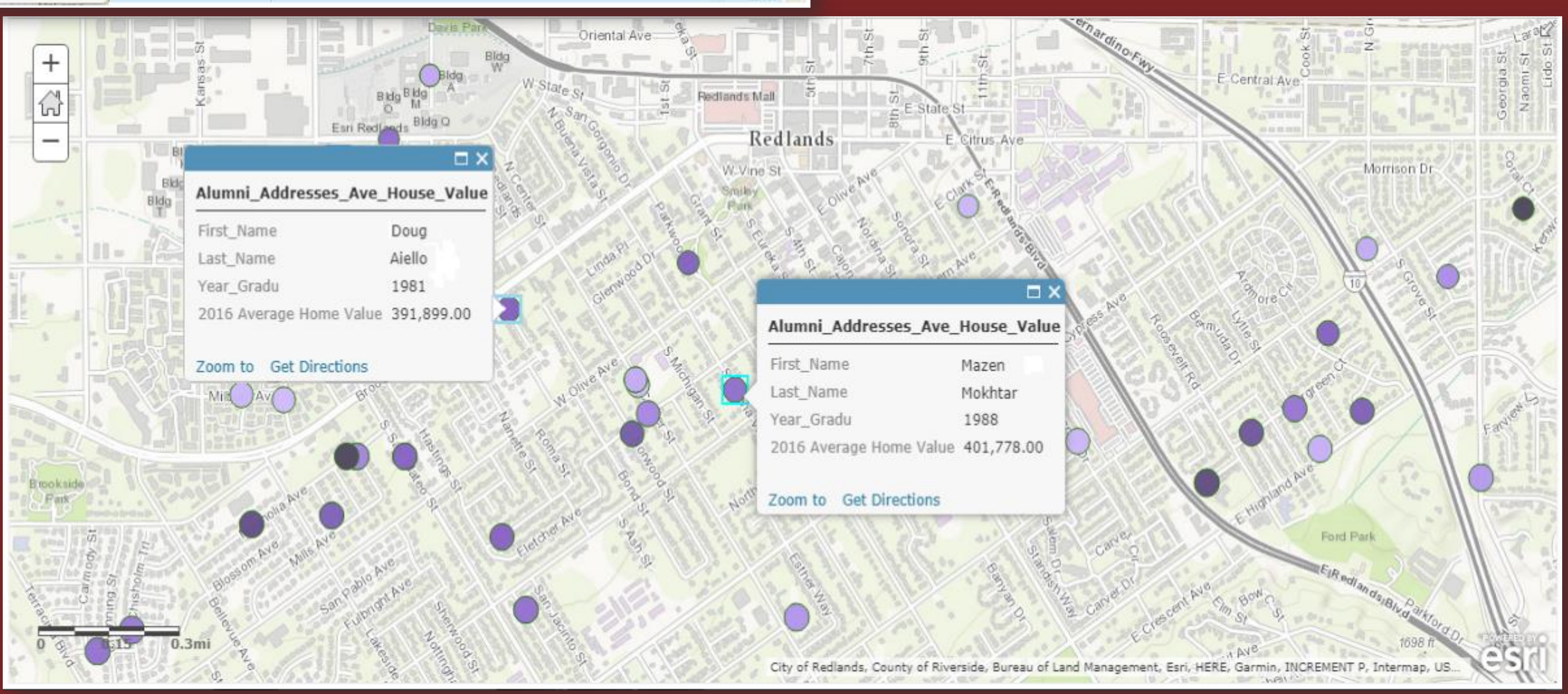

\section{Solution:}

The solution involved the creation of a geodatabase in ArcGIS that contains information on current students and alumni, such as, first name, last name, and full georeferenced address. By analyzing the information contained in the geodatabase, an interactive map was created through ArcGIS Online that includes median household value. The interactive map will display layers of information that can be navigated through by the user so they can view all students and alumni in the entire United States. They are symbolized with different color point symbols that the user can click on to access pop-ups.
Email: Eng-mazen_mokhtar@hotmail.com

Phone: 858-999-6694 